Acta Cryst. (1988). A44, 231-232

\section{LOGO DESIGN CONTEST}

PRIZE: US\$ 1000 in IUCr publications or US\$ 600 in cash, as chosen by the winner

Entries are invited for the design of a LOGO for the International Union of Crystallography.

\section{Conditions}

(1) All designs must be received by the

IUCr Logo Committee,

c/o Professor Kaarle Kurki-Suonio,

Department of Physics,

University of Helsinki,

Siltavuorenpenger $20 \mathrm{D}$, SF-00170 Helsinki, Finland

Telephone 3580650211 , Telex 122229 nuphu sf, Telefax 3580656591

on, or before, the closing date of 15 July 1988.

(2) The selection of the winning logo will be the responsibility of the IUCr Logo Committee subject to the approval by the Executive Committee. The winning entrant will be informed directly and the winner's name will be published in Acta Crystallographica and Journal of Applied Crystallography.

(3) Each entrant is limited to a maximum of three designs.

(4) The logo suggestion should be transmitted by registered mail and must be submitted under a pseudonym. The entrant's real name and address must be supplied in a sealed envelope, which will be opened only in the case of the winner, when the decision has been made. The entries will not be returned after the competition.

(5) The designs should be drawn on sheets not larger than the standard A3 size $(29.7 \mathrm{~cm} \times 42.0 \mathrm{~cm})$.

(6) No correspondence will be entered into after the closing date. Enquiries prior to the closing date should be directed to any of the members of the Logo Committee: Professor Kaarle Kurki-Suonio (address above), Professor Sydney R. Hall (Telephone: 3802725 or 3802738 . Address: Crystallography Centre, University of Western Australia, Nedlands, Western Australia 6009, Australia) or Dr Moreton Moore (Telephone: 0784 39941, Telex 935504. Address: Department of Physics, Royal Holloway and Bedford New College, University of London, Egham, Surrey TW20 0EX, England).

(7) The winning logo will become the sole property of the IUCr and may not be used, printed or copied for any purpose without the express written permission of the Executive Committee.

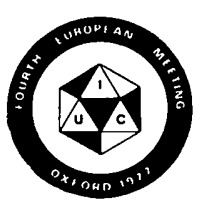

(a)

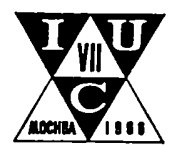

(b)

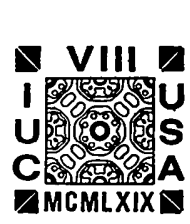

(c)

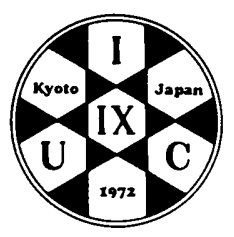

(d)

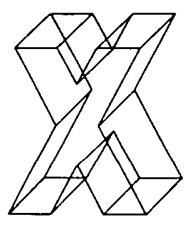

(e)

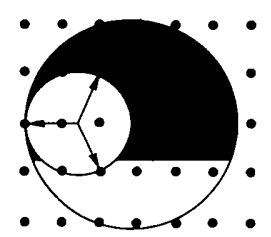

(h)

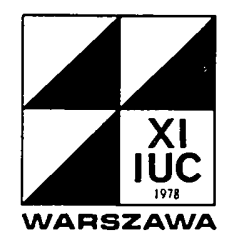

(f)

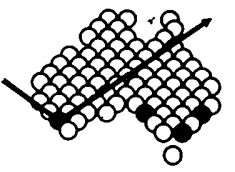

(i)

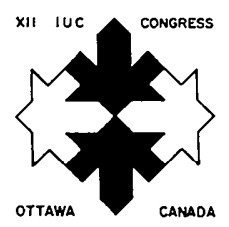

(g)

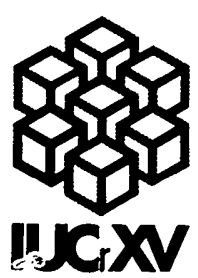

(j)

Fig. 1. Some logos for crystallographic conferences. (a) Fourth European Crystallographic Meeting, Oxford, England, 30 August-3 September 1977. (b) IUCr VII, Moscow, USSR, 12-19 July 1966. (c) IUCr VIII, Stony Brook, USA, 13-21 August 1969. (d) IUCr IX, Kyoto, Japan, 26 August-7 September 1972. (e) IUCr X, Amsterdam, The Netherlands, 7-15 August 1975. ( $f$ ) IUCr XI, Warsaw, Poland, 3-12 August 1978. (g) IUCr XII, Ottawa, Canada, 16-25 August 1981. (h) IUCr XIII, Hamburg, Federal Republic of Germany, 9-18 August 1984. (i) IUCr XIV, Perth, Australia, 12-20 August 1987. (j) IUCr XV, Bordeaux, France, 19-28 July 1990. 
(8) The IUCr reserves the right to buy any of the designs for other purposes, for example for the basis of the logos of the IUCr Congresses.

(9) The Committee reserves the right to contact the entrant with recommended changes to a submitted logo prior to the announcement of the winner.

\section{Information}

The Logo will be used for IUCr publications, letterheads, brochures and other purposes as may be decided by the
Executive Committee. The logo may depict or represent any aspect of the field of crystallography or of the IUCr. In the past, logos for crystallographic conferences ( $c f$. Fig. 1) have tended to represent some aspect of crystals, symmetry or diffraction - subjects which are fundamental to crystallography. The logo may contain the initials I U Cr, but this is not essential. Use of colour is allowed, but more than two colours is discouraged and the main use of the logo will be in black and white.

\section{Notes and News}

Acta Cryst. (1988). A44, 232

\section{Standard Crystallographic File Structure-87}

How often have you been frustrated by finding that your datafile was in the wrong format for your program? And how much time have you spent in writing conversion programs to change data from one format to another?

In order to minimize these problems, the Data and Computing Commissions of the International Union of Crystallography approved, in 1981, a Standard Crystallographic File Structure (Acta Cryst. A39, 216-224). This describes a file structure that can be used to store or transfer most kinds of crystallographic data and, at the same time, is easy to program and is adaptable to individual user's needs. Since 1981 the standard has been enhanced and in the most recent release (SCFS-87) it can include all the information (including text, tables and supplementary material) required for a short structural paper in Acta Crystallographica including the text. It is designed not only for giving structural data, but it can also include data as different as powder patterns and protein derivative structure factors.

Copies of the latest standard can be obtained from: Dr I. D. Brown, Institute for Materials Research, McMaster University, Hamilton, Ontario, Canada L8S 4M1. 1002332@mcmaster.netnorth

It is available in either hardcopy form or as a machinereadable file which maybe sent over the NetNorth/Bitnet/Earn networks. A user-adaptable program to read an SCFS-87 file is available by network from: Dr H. D. Flack, Laboratoire de Cristallographie, Université de Genève, 24 quai Ernest-Ansermet, 1211 Genève 4, Switzerland."flack@cgeuge52"

Acta Cryst. (1988). A44, 232

\section{Publish your Crystallographic Computer Programs}

A large number of new crystallographic computer programs (or modifications to existing programs) presented at international and national conferences, summer schools, private demonstrations, or referred to only passingly in other publi- cations remain unpublished. Consequently, potential users are deprived of valuable information and access to state-ofthe-art computer code. The IUCr Commission on Crystallographic Computing is well aware of this problem and is particularly anxious to encourage authors of computer programs to publish their software. The journal of choice for crystallographic computer programs is:

Journal of Applied Crystallography - a publication of the IUCr - which provides two categories of publication concerned with crystallographic computer programs: Computer Programs is intended for complete articles giving in-depth information on the program and algorithm whereas Computer Program Abstracts provides a condensed format that contains only essential details.

In Computer Programs, a brief description of the purpose, strategy, computer language, machine requirement, input requirements and the type of results obtained should be included. Ordinarily, it is required also that the adequacy of the documentation shall have been proven by the successful use of the program by someone outside the authors' institution. Examples of Computer Programs are: TREOR, a semi-exhaustive trial-and-error powder indexing program for all symmetries [Werner, P.-E., Eriksson, L. \& Westdahl, M. (1985). J. Appl. Cryst. 18, 367-370]; STRUPLO84, a Fortran plot program for crystal structure illustrations in polyhedral representation [Fischer, R. X. (1985). J. Appl. Cryst. 18, 258-262]. Notes for Authors may be found in Acta Cryst. (1983), A39, 174-186 and a checklist in J. Appl. Cryst. (1985), 18, 1-2.

Computer Program Abstracts provides a rapid means of communicating up-to-date information concerning both new programs or systems and significant updates to existing programs. Following normal submission, a Computer Program Abstract will be reviewed by one or two members of the IUCr Commission on Crystallographic Computing. It should not exceed 500 words in length and should use the standard format given in J. Appl. Cryst. (1985), 18, 189-190. Examples of publications in this category are: PATMET program for determination of orientation and position of a known fragment in the unit cell [Wilson, C. C. \& Tollin, P. (1986). J. Appl. Cryst. 19, 411-412]; DREAM - data reduction and error analysis routines for accurate singlecrystal diffraction intensity measurements [Blessing, $\mathrm{R}$. $\mathrm{H}$. (1986). J. Appl. Cryst. 19, 412]. 